\title{
Effect of statins on aortic root growth rate in patients with bicuspid aortic valve anatomy
}

\author{
Madelien V. Regeer ${ }^{1} \cdot$ Philippe J. van Rosendael ${ }^{1} \cdot$ Vasileios Kamperidis $^{1}$ • \\ Martin J. Schalij ${ }^{1} \cdot$ Jeroen J. Bax $^{1} \cdot$ Nina Ajmone Marsan $^{1} \cdot$ Victoria Delgado $^{1,2}$
}

Received: 15 June 2015/Accepted: 18 August 2015/Published online: 29 August 2015

(c) The Author(s) 2015. This article is published with open access at Springerlink.com

\begin{abstract}
Bicuspid aortic valve (BAV) anatomy is associated with increased growth rate of the aortic root compared to tricuspid aortic valves. Statins decrease the growth rate of abdominal aneurysms; however their effect on the aortic root growth rate has not been elucidated. The present study evaluated the association between use of statins and aortic root growth in patients with BAV. A total of 199 patients $(43 \pm 15$ years, $69 \%$ male $)$ with BAV who underwent $\geq 2$ echocardiographic measurements of the aortic root $\geq 1$ year apart were included in this retrospective observational study. Median follow-up duration was 4.7 years (interquartile range $2.7-8.3$ years). Growth rate $(\mathrm{mm} /$ year) of the aortic root was compared between statin users $(n=41)$ and non-users $(n=158)$. Statin users were significantly older and had more cardiovascular risk factors than their counterparts. Ascending aorta diameter was significantly smaller at baseline and at follow-up in statin users compared with non-users when adjusted for coronary artery disease, age and medication. The average annual growth rate was $0.08 \mathrm{~mm} /$ year $(95 \%$ confidence interval $0.03-0.13$ ) for the aortoventricular junction, $0.16 \mathrm{~mm} /$ year $(0.11-0.21)$ for the sinus of Valsalva, $0.12 \mathrm{~mm} / \mathrm{year}$ $(0.07-0.17)$ for the sinotubular junction and $0.45 \mathrm{~mm} / \mathrm{year}$ $(0.37-0.53)$ for the ascending aorta. The dilation rate of the aortic segments was not different between statin users and non-users. In conclusion, in patients with BAV, although the use of statins was associated with smaller ascending
\end{abstract}

Victoria Delgado

v.delgado@lumc.nl

1 Heart Lung Center Leiden, Leiden University Medical Center, Leiden, The Netherlands

2 Department of Cardiology, Leiden University Medical Center, Albinusdreef 2, 2333 ZA Leiden, The Netherlands aorta, the annual dilation rate of the aortic root was not influenced by the use of statins.

Keywords Bicuspid aortic valve - Aortic dilation Echocardiography · 3-Hydroxy-3-methylglutaryl coenzyme A reductase inhibitors

\section{Introduction}

Patients with bicuspid aortic valve (BAV) anatomy have shown larger aortic root diameters and faster growth rate of the ascending aorta compared with patients with tricuspid aortic valve (TAV) anatomy leading to an excess risk of dissection and rupture in the former patients [1]. The average growth rate of the ascending aorta in patients with BAV is $0.77 \mathrm{~mm} /$ year, fivefold higher than that of agematched TAV patients [2]. Pathophysiological factors associated with the increased prevalence of ascending aorta dilation and faster growth rate among BAV patients include abnormal wall stress distribution (particularly in patients with dysfunctional aortic valves), altered aortic wall structure and/or an underlying genetic substrate [3]. Specifically, increased activity and expression of metalloproteinases have been demonstrated in histological samples of ascending aorta aneurysms of patients with BAV [4]. The pleiotropic effects of 3-hydroxy-3-methylglutaryl coenzyme A reductase inhibitors (statins) reduce the expression of metalloproteinases $[5,6]$ and have been demonstrated to limit the growth rate of abdominal aneurysms and to improve the thoracic and abdominal aortic aneurysm rupture and dissection-free survival [7-11]. In patients with $\mathrm{BAV}$, the use of statins has been associated with smaller aortic root and ascending aorta diameters in cross-sectional 
studies [12]. However, the effect of statins on the aortic root and ascending aorta growth rate of these patients remains unclear. Accordingly, we evaluated the effect of statins on the aortic root and ascending aorta growth rates of patients with BAV in a retrospective study.

\section{Methods}

\section{Patients}

The present retrospective study included patients aged $\geq 18$ years with BAV who underwent transthoracic echocardiography surveillance from 1995 to 2014 for at least 1 year. If patients underwent aortic valve and/or aortic root surgery during follow-up, the last transthoracic echocardiography before surgery was selected for analysis. Patients with complex congenital heart disease, connective tissue disease and subvalvular aortic stenosis were not included. In total 262 patients were eligible for inclusion. From this group, 48 patients with coarctation of the aorta and 15 patients with an ascending aorta of $\geq 45 \mathrm{~mm}$ at baseline were excluded. The final cohort consisted of 199 patients (Fig. 1).

Demographic and clinical characteristics were collected in the departmental Cardiology Information System (EPD-Vi$\operatorname{sion}^{\circledR}$, Leiden University Medical Center, Leiden, The Netherlands) and retrospectively analyzed. Medication use (statins, angiotensin converting enzyme-inhibitors/angiotensin receptor blockers and beta-blockers) were obtained from chart review. Patients were divided into two groups: patients treated with statins for at least $50 \%$ of the follow-up time (statin users) and patients not treated with statins (nonusers). Aortic root diameters were measured at four levels and annual growth rate in $\mathrm{mm} /$ year was compared between the two groups. The institutional review board approved this retrospective analysis of clinically acquired data and waived the need for patient written informed consent.

\section{Two-dimensional transthoracic echocardiography}

Transthoracic echocardiography was performed using commercially available ultrasound systems (System Five, Vivid 7, and E9, General Electric Healthcare, Vingmed, Horten, Norway) equipped with $3.5-\mathrm{MHz}$ or M5S transducers. Parasternal and apical views were obtained at rest with patients in the left decubitus position while subcostal and supra-sternal views were obtained with patients in supine position. Two-dimensional, M-mode and Doppler data were acquired according to current recommendations [13]. The echocardiographic data were digitally stored in cine-loop format and data were retrospectively analysed off-line using commercially available software (EchoPac 112.0.1, GE Medical Systems, Horten, Norway). Left ventricular (LV) end-diastolic and end-systolic diameters were measured in the M-mode parasternal long-axis view recordings. LV end-diastolic and end-systolic volumes were measured in the apical 2- and 4-chamber views and LV ejection fraction was calculated according to the Simpson's biplane method [13].

BAV was diagnosed on the parasternal short-axis view of the aortic valve by the presence of two commissures in systole [14]. BAV was typical when the commissures were oriented at 4-10, 5-11 or 3-9 o'clock and atypical when the commissures were oriented at 1-7 or 12-6 o'clock. The presence of a raphe was noted [14]. Aortic valve function was evaluated using colour-Doppler, continuous- and pulsed-wave Doppler. Valvular dysfunction was defined as pure aortic regurgitation when $\geq$ grade 2 and less then mild aortic stenosis, pure aortic stenosis when $\geq$ moderate and aortic regurgitation $\leq$ grade 1 or mixed aortic valve disease $[15,16]$.
Fig. 1 Flowchart of patient inclusion

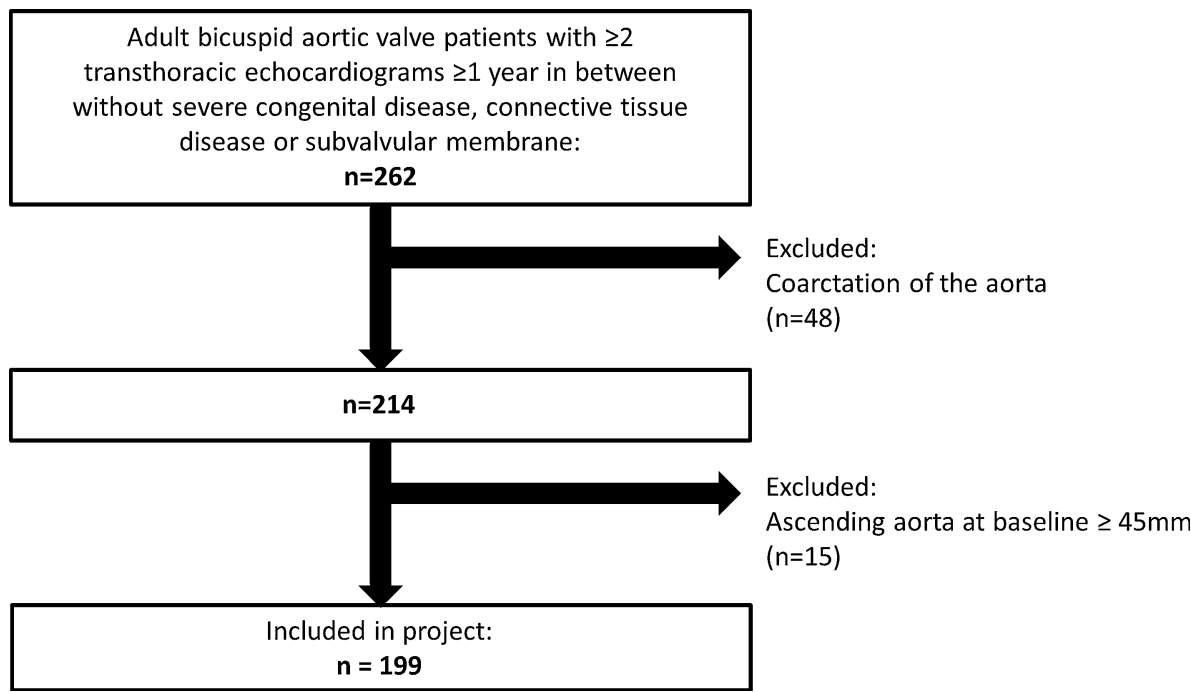


Aortic root dimensions were measured using the leading edge-to-leading edge technique during end-diastole in the parasternal long-axis view perpendicular to the long-axis of the aorta at four predefined levels: (1) the aortoventricular junction (AVJ) defined as the hinge points of the aortic leaflets, (2) the sinuses of Valsalva (SOV), (3) the sinotubular junction (STJ) and (4) the ascending aorta (AAo) (4 $\mathrm{cm}$ distal from the aortic valve) $[17,18]$.

\section{Statistical analysis}

Continuous variables were reported as mean \pm standard deviation or median and interquartile range when appropriate. Categorical variables were reported as numbers and percentages. Continuous and categorical variables were compared with the Student's $t$ test (or Mann-Whitney $U$ test in non-normally distributed variables) and Chi square test, respectively. Differences in aortic root diameters at baseline and follow-up between groups were assessed with ANOVA test for repeated measures. Statin use was incorporated in the model as factor together with coronary artery disease, use of beta-blockers and the use of angiotensin converting enzymeinhibitors or angiotensin receptor blockers. Age at baseline was incorporated in the model as covariate. Estimated marginal mean \pm standard error of the mean for the aortic root diameters were reported for statin users and non-users at baseline and during follow-up. Regression analysis was used to assess the difference in aortic root growth rate in $\mathrm{mm} / \mathrm{year}$ between statin users and non-users following the previously described instrumental variables approach [19]. Assuming that the aortic root growth is linear, the estimate of the association between aortic root growth and the follow-up was obtained by linear regression analysis without including an intercept. Next statin use multiplied by follow-up duration in years was introduced to assess the additive value of statin use on the growth of the aortic root in $\mathrm{mm} /$ year. Intraobserver variability was assessed using Bland-Altman method measuring 20 echocardiograms repeatedly by one observer. Similarly, inter-observer variability was assessed by performing the measurements by two independent observers at least 1 week apart. All statistical tests were twosided. A $p$ value $<0.05$ was considered statistically significant. Data analyses were performed using the SPSS software (Version 20.0. Armonk, NY: IBM Corp).

\section{Results}

A total of 199 patients (mean age $43 \pm 15$ years, $69 \%$ men) were included in the present analysis. There were 41 (21\%) statin users and $158(79 \%)$ non-users. Baseline characteristics are presented in Table 1. Among statin users, the median duration of the treatment was 3.5 years (interquartile range 2.4-5.4 years). The types and doses of statins varied over time and were adjusted to patient's tolerance. The majority of patients received simvastatin (usually 20 or $40 \mathrm{mg}$ daily) or rosuvastatin (usually $10 \mathrm{mg}$ daily). Other types of statins used were atorvastatin and pravastatin (usually 20 or $40 \mathrm{mg}$ daily). Statin users were significantly older, with greater incidence of coronary artery disease, hypertension and New York Heart Association II-III functional class heart failure symptoms. Furthermore, statin users received more frequently angiotensin converting enzyme-inhibitors/angiotensin receptor blockers and beta-blockers. There was no significant difference between groups in total cholesterol levels at baseline. However, in statin users there was a tendency towards higher LDL-cholesterol and higher triglycerides. Furthermore the HDL-cholesterol was significantly lower in statin users compared to their counterparts. There was no significant difference in LV end-diastolic and end-systolic dimensions. Statin users had slightly lower LV ejection fraction compared to non-users $(51 \pm 7$ vs. $53 \pm 7 \%$; $p=0.054)$. The presence of a raphe, type of BAV and aortic valvular dysfunction was not significantly different between statin-users and non-users.

Echocardiographic follow-up was complete with a median follow-up duration of 5.1 years (interquartile range 2.7-8.8 years) in non-users and 3.9 years (interquartile range $2.6-5.5$ years $)$ in statin users $(p=0.052)$. Figure 2 shows the differences in aortic root diameters at baseline and during follow-up between the groups, using the ANOVA test for repeated measurements adjusted for age at baseline, the presence of coronary artery disease and the use of angiotensin converting enzyme-inhibitors or angiotensin receptor blockers and beta-blockers. The aortic root diameter at the level of the AVJ was not significantly different between statin users and non-users. Aortic root diameter at the level of the SOV was comparable at baseline and at follow-up in statin users $(32.7 \pm 0.8$ and $33.5 \pm 0.9 \mathrm{~mm})$ compared to non-users $(34.3 \pm 0.8$ and $35.2 \pm 0.9 \mathrm{~mm}$ ). At the level of the STJ, the diameter was significantly smaller in statin users compared to non-users at baseline $(27.8 \pm 0.8$ vs. $30.3 \pm 0.8 \mathrm{~mm} ; p=0.013)$. However, there was no significant difference in STJ diameter at follow-up. The AAo was significantly smaller in statin users compared to non-users at baseline ( $30.8 \pm 0.9$ vs. $34.7 \pm 0.9 \mathrm{~mm} ; p=0.001)$ and at followup $(33.2 \pm 1.0$ vs. $36.3 \pm 1.0 \mathrm{~mm} ; p=0.014)$.

The average annual aortic growth rate was $0.08 \mathrm{~mm} /$ year (95\% confidence interval 0.03-0.13) for the AVJ, $0.16 \mathrm{~mm} /$ year $(0.11-0.21)$ for the SOV, $0.12 \mathrm{~mm} /$ year $(0.07-0.17)$ for the STJ and $0.45 \mathrm{~mm} /$ year $(0.37-0.53)$ for the AAo. There was no significant additive value of statin use on the annual growth rate of the aortic segments as presented in Table 2. 
Table 1 Baseline characteristics

\begin{tabular}{|c|c|c|c|}
\hline Variable & Non-users $(\mathrm{n}=158)$ & Statin users $(n=41)$ & $p$ value \\
\hline Age (years) & $40 \pm 14$ & $55 \pm 10$ & $<0.001$ \\
\hline Male & $106(67 \%)$ & $31(76 \%)$ & 0.389 \\
\hline Body surface area $\left(\mathrm{m}^{2}\right)$ & $1.93 \pm 0.23$ & $1.98 \pm 0.21$ & 0.189 \\
\hline Smoking & $29(18 \%)$ & $12(29 \%)$ & 0.186 \\
\hline Diabetes & $4(3 \%)$ & $3(7 \%)$ & 0.314 \\
\hline Hypertension & $26(16 \%)$ & $14(34 \%)$ & 0.021 \\
\hline NYHA functional class & & & $<0.001$ \\
\hline I & $145(91 \%)$ & $27(66 \%)$ & \\
\hline II & $9(6 \%)$ & $12(29 \%)$ & \\
\hline III & $4(3 \%)$ & $2(5 \%)$ & \\
\hline IV & $0(0 \%)$ & $0(0 \%)$ & \\
\hline Previous cardiac surgery & $4(3 \%)$ & $4(10 \%)$ & 0.098 \\
\hline Coronary artery disease & $1(1 \%)$ & $15(37 \%)$ & $<0.001$ \\
\hline ACE-inhibitor or ARB & $32(20 \%)$ & $25(61 \%)$ & $<0.001$ \\
\hline Beta-blocker & $32(20 \%)$ & $24(59 \%)$ & $<0.001$ \\
\hline Total cholesterol (mg/dl) & $195 \pm 36$ & $198 \pm 47$ & 0.690 \\
\hline LDL cholesterol (mg/dl) & $120 \pm 32$ & $136 \pm 46$ & 0.071 \\
\hline Triglycerides (mg/dl) & $128 \pm 63$ & $154 \pm 85$ & 0.081 \\
\hline HDL cholesterol (mg/dl) & $57 \pm 17$ & $49 \pm 14$ & 0.028 \\
\hline LV end-diastolic diameter (mm) & $50 \pm 6$ & $49 \pm 6$ & 0.160 \\
\hline LV end-systolic diameter (mm) & $31 \pm 6$ & $31 \pm 7$ & 0.994 \\
\hline LV end-diastolic volume (ml) & $131 \pm 39$ & $120 \pm 27$ & 0.089 \\
\hline LV end-systolic volume (ml) & $62 \pm 24$ & $59 \pm 17$ & 0.450 \\
\hline LV ejection fraction $(\%)$ & $53 \pm 7$ & $51 \pm 7$ & 0.054 \\
\hline Atypical bicuspid aortic valve & $45(28 \%)$ & $11(27 \%)$ & 0.988 \\
\hline Raphe & $135(85 \%)$ & $37(90 \%)$ & 0.586 \\
\hline Valvular dysfunction & & & 0.274 \\
\hline None & $99(63 \%)$ & $27(66 \%)$ & \\
\hline Pure aortic regurgitation & $27(17 \%)$ & $6(15 \%)$ & \\
\hline Pure aortic stenosis & $21(13 \%)$ & $8(19 \%)$ & \\
\hline Mixed aortic disease & $11(7 \%)$ & $0(0 \%)$ & \\
\hline
\end{tabular}

Data are presented as mean $\pm \mathrm{SD}$ or as number (percentage)

$A C E$ angiotensin converting enzyme, $A R B$ angiotensin receptor blocker, $H D L$ high density lipoprotein, $L D L$ low density lipoprotein, $L V$ left ventricular, NYHA New York Heart Association
The intra-observer variability, displayed as 1.96 times the standard deviation of the difference between the two measurements was $1.6 \mathrm{~mm}$ for the AVJ, $3.2 \mathrm{~mm}$ for the SOV , $4.2 \mathrm{~mm}$ for the STJ and $5.1 \mathrm{~mm}$ for the AAo. The inter-observer variability was $2.6 \mathrm{~mm}$ for the AVJ, $3.9 \mathrm{~mm}$ for the SOV, $4.3 \mathrm{~mm}$ for the STJ and $4.4 \mathrm{~mm}$ for the AAo.

\section{Discussion}

The main results of the present observational study can be summarized as follows: among patients with BAV, those treated with statins had smaller STJ at baseline and smaller AAo at baseline and at follow-up compared with patients non-treated with statins after correcting for age, presence of coronary artery disease and the use of angiotensin converting enzyme-inhibitors or angiotensin receptor blockers and beta-blockers. However, there was no significant effect of statins on the annual aortic growth rate since this was comparable between both subgroups of patients.

Bicuspid aortic valve is the most frequent congenital heart disease with an estimated prevalence of $1.3 \%$ in the general population [20]. In addition, BAV anatomy is associated with aortopathy and increased prevalence of aneurysms of the ascending aorta which occur at a younger age than in TAV $[2,21]$. Specific genotypes, histological and inmunohistochemical factors and changes in hemodynamics with increased shear stress on the aortic wall have been associated with increased risk of ascending aortic dilation in patients with BAV [21-23]. Indeed, in patients 
with BAV the growth rate of the aortic root and ascending aorta ranges between 0.2 and $0.9 \mathrm{~mm} /$ year [9, 24], a growth rate relatively similar to that observed in patients
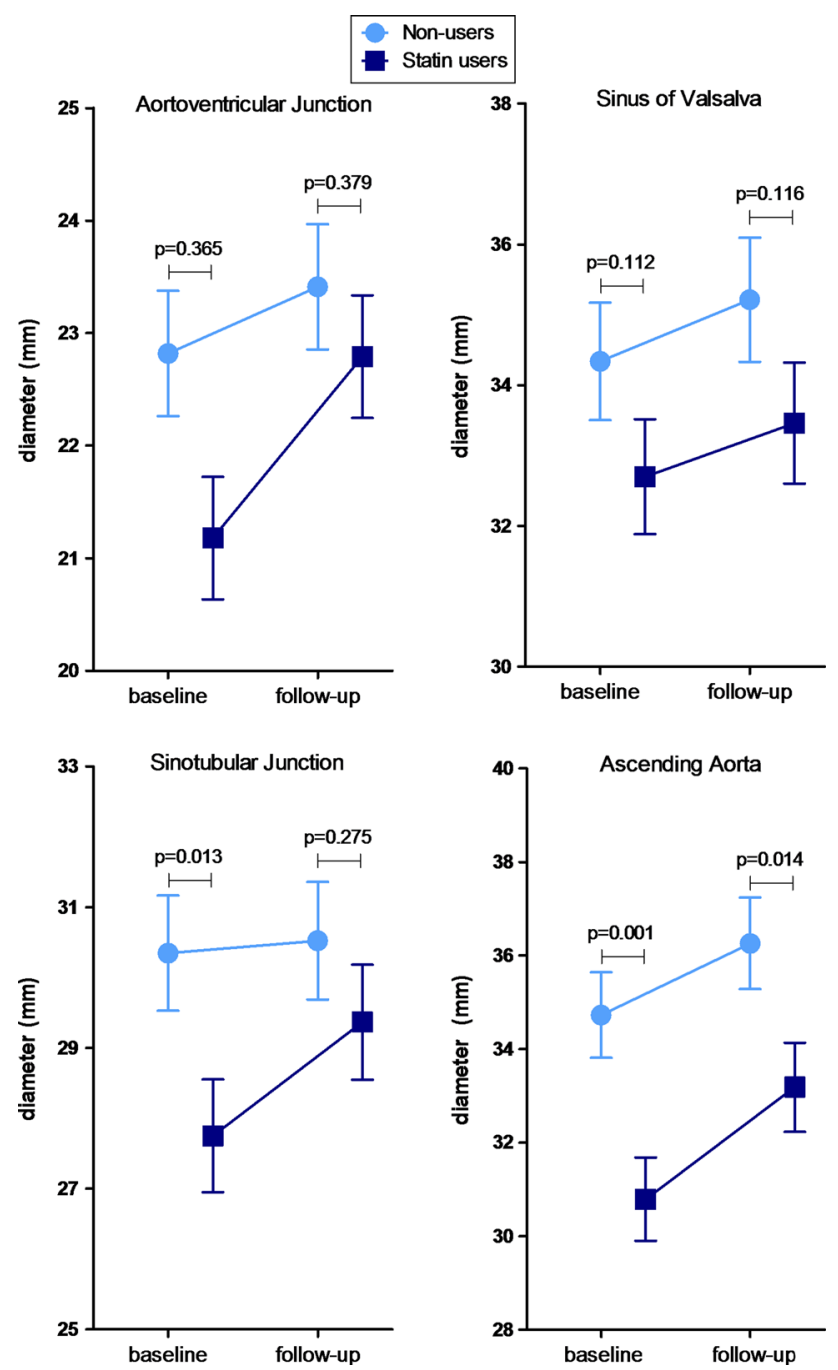

Fig. 2 Comparison of aortic diameters at baseline and at follow-up between statin users and non-users. Data are presented as estimated marginal mean \pm standard error of the mean calculated for mean age at baseline of 43 years and corrected for the presence of coronary artery disease and the use of angiotensin converting enzymeinhibitors or angiotensin receptor blockers and beta-blockers with Marfan syndrome but significantly different from that of patients with TAV and degenerative aortopathy [24]. In a recent study involving 353 patients with BAV who were compared with 51 patients with degenerative aortopathy and 50 patients with Marfan syndrome, Detaint et al. [24] showed that in patients with BAV the maximal dilation rate was $0.42 \pm 0.6 \mathrm{~mm} /$ year while in patients with Marfan syndrome and in patients with degenerative aortopathy the maximal dilation rate was $0.49 \pm 0.5$ and $0.20 \pm 0.3 \mathrm{~mm} /$ year, respectively $(p=0.02)$. Interestingly, the growth rate was largest at the ascending aorta in patients with BAV $(0.42 \pm 0.6 \mathrm{~mm} /$ year $)$ while in patients with Marfan syndrome, the sinuses of Valsalva showed the largest growth rate $(0.49 \pm 0.5 \mathrm{~mm} /$ year $)$. The present study shows similar growth rates for each level of the aortic root and ascending aorta to those reported by Detaint et al. with the ascending aorta as the segment with the largest growth rate. However, Detaint et al. [24] did not find an independent association between aortic growth rate and the use of angiotensin converting enzyme inhibitors, angiotensin receptor blockers or beta-blockers. The present study also did not find an association between the use of angiotensin converting enzyme-inhibitors/angiotensin receptor blockers and beta-blockers and the aortic root diameters at baseline and during follow-up. In contrast, the present study provides information on the association between statin use and the aortic growth rate of these patients.

The pathogenesis of ascending aorta dilation in patients with BAV is multifactorial and, in contrast to abdominal aortic aneurysms, ascending aorta aneurysms do not result in atherosclerosis [25]. However, in patients with BAV, there is an increased expression and activity of metalloproteinases that degrade the type IV collagen, elastin and fibrillar collagens [4]. Statins, clinically used as lipid lowering drugs, have various anti-inflammatory and pleiotropic effects [6]. Therefore it has been hypothesized that statins may have an inhibitory effect on aneurysm formation. For example, in experimental models statins have shown to inhibit the progression of abdominal aortic aneurysms independently of the total serum cholesterol levels lowering effect $[5,6]$. Inhibition of macrophage infiltration into the aorta and preservation of aortic wall elastin and medial smooth muscle cells

Table 2 Average annual growth rates in mm/year per aortic segment with the additive effect of the use of statins on the annual growth rate

\begin{tabular}{|c|c|c|c|c|}
\hline \multirow[t]{2}{*}{ Variable } & \multicolumn{2}{|c|}{ Annual growth rate } & \multicolumn{2}{|c|}{ Additive effect of the use of statins on annual growth rate } \\
\hline & $\mathrm{B}(95 \% \mathrm{CI})$ & $p$ value & $\mathrm{B}(95 \% \mathrm{CI})$ & $p$ value \\
\hline Aortoventricular junction & $0.08(0.03-0.13)$ & 0.001 & $-0.03(-0.16$ to 0.11$)$ & 0.687 \\
\hline Sinus of Valsalva & $0.16(0.11-0.21)$ & $<0.001$ & $-0.06(-0.20$ to 0.08$)$ & 0.413 \\
\hline Sinotubular junction & $0.12(0.07-0.17)$ & $<0.001$ & $0.13(-0.02$ to 0.28$)$ & 0.079 \\
\hline Ascending aorta & $0.46(0.37-0.54)$ & $<0.001$ & $-0.05(-0.27$ to 0.17$)$ & 0.671 \\
\hline
\end{tabular}

Data are presented as regression coefficient (B) and $95 \%$ confidence interval (95\% CI) indicating annual growth rates in $\mathrm{mm} / \mathrm{year}$ 
in the aortic wall are the main underlying mechanisms explaining those findings $[5,6]$.

Clinical experiences have shown that patients with BAV who receive statin therapy have smaller ascending aorta diameters compared to non-users [12]. In 147 patients with BAV undergoing aortic valve replacement with or without aortic root replacement, Goel et al. showed that patients treated with statins had significantly smaller ascending aorta diameters than patients not receiving statins $(3.6 \pm 0.7$ vs. $3.9 \pm 0.6 \mathrm{~cm}, p<0.001)$ and the use of statins was independently associated with a $0.33 \mathrm{~cm}$ reduction in aortic size [12]. Furthermore, Jovin et al. [9] showed that in patients with thoracic aneurysms (without specifying the prevalence of BAV), the annual growth rate of the thoracic aortic aneurysm in patients treated with statins $(n=46)$ was comparable to that of patients not treated with statins $(\mathrm{n}=169)(0.8$ vs. $0.9 \mathrm{~mm} /$ year, $p=0.7)$. Angeloni et al. [11] recently published a large propensity score matched cohort study that showed a significantly smaller ascending aorta dilation rate of $0.95 \mathrm{~mm} / \mathrm{year}$ in statin users compared to $1.27 \mathrm{~mm} /$ year in non-users. The reported dilation rates were both larger than those reported in the present study, which might be explained by the inclusion of larger ascending aortic aneurysms at baseline in the study by Angeloni et al. [11]. However, it should be emphasized that the anatomy of the aortic valve was not specified and that the age of the population was older than that of the patients included in our study and therefore, the results reported by Angeloni and coworkers may not be extrapolated to a younger BAV patient cohort.

\section{Clinical implications}

Ascending aorta dilation is the second most common morbidity in patients with BAV [1]. Due to the associated risk of aneurysm rupture, identification of pathophysiological determinants and potential therapeutic targets to reduce the risk of aortic dilation is a cardiovascular research priority. Besides advances in multimodality imaging that permit accurate diagnosis and characterization of BAV and its hemodynamics; genetic- and biomarkerbased risk stratification may help to identify those patients at increased risk of aortic dilation. In addition, prospective studies evaluating the effect of specific therapies such as statins that may reduce the expression and activity of metalloproteinases or angiotensin converting enzymes inhibitors that may favourably affect the shear strain of the aortic wall are needed.

\section{Limitations}

The present study, taking into consideration all the limitations of an observational retrospective design, shows that the use of statins is associated with smaller aortic root and ascending aorta dimensions in patients with BAV but does not influence the growth rate. Therefore, it cannot be concluded that BAV patients without an indication for statins, should use a statin as primary prevention for aortic dilation. The relatively small number of patients treated with statins is also another limitation. In addition, patients using statins were different from non-users regarding age, presence of coronary artery disease and the use of angiotensin converting enzyme-inhibitors, angiotensin receptor blockers and beta-blockers. We corrected the statistical analysis for these important confounding factors. However, the influence of potential other unknown confounding factors could not be taken into account. Prospective trials with appropriate sample sizes randomizing patients to statin treatment or placebo are needed to assess the isolated effect of statins on aortic root dilation excluding potential confounding factors (such as cardiovascular risk factors and other drugs used). Other limitations of the present study include the evaluation of a selected cohort of patients with at least two echocardiographic studies $\geq 1$ year of follow-up. This may have introduced selection bias, since patients with large or rapid growing aneurysms will be referred immediately for surgery. Furthermore, compared with other imaging techniques that provide higher spatial resolution data, transthoracic echocardiography may provide less accurate measurements of the aortic root and ascending aorta diameters. However, in this study we used linear regression analysis to assess the dilation rate following the previously described instrumental variables approach which mitigates problems associated with random errors such as measurement variability [19]. There was a wide variety in the type and doses of drugs taken by the patients included in the present study. Also within patients, the type and dose of drug could change during follow-up. Therefore a more precise analysis per type and dose of statins was not feasible. Future studies may provide further insight into the differences between types of statins and their effects on the aortic root dilation rate.

\section{Conclusions}

In conclusion, in patients with $\mathrm{BAV}$, the use of statins is associated with smaller STJ and AAo diameters when corrected for confounding factors. However, the annual growth rate of the aortic root and ascending aorta was not influenced by the use of statins.

\section{Compliance with ethical standards}

Conflict of interest The Department of Cardiology received grants from Biotronik, Medtronic and Boston Scientific Corporation. Dr. 
Victoria Delgado received speaker fee from Abbott Vascular. The remaining authors have no financial or other conflicts of interest.

Open Access This article is distributed under the terms of the Creative Commons Attribution 4.0 International License (http://crea tivecommons.org/licenses/by/4.0/), which permits unrestricted use, distribution, and reproduction in any medium, provided you give appropriate credit to the original author(s) and the source, provide a link to the Creative Commons license, and indicate if changes were made.

\section{References}

1. Michelena HI, Khanna AD, Mahoney D, Margaryan E, Topilsky Y, Suri RM, Eidem B, Edwards WD, Sundt TM 3rd, EnriquezSarano M (2011) Incidence of aortic complications in patients with bicuspid aortic valves. JAMA 306:1104-1112

2. Etz CD, Zoli S, Brenner R, Roder F, Bischoff M, Bodian CA, DiLuozzo G, Griepp RB (2010) When to operate on the bicuspid valve patient with a modestly dilated ascending aorta. Ann Thorac Surg 90:1884-1890

3. El-Hamamsy I, Yacoub MH (2009) A measured approach to managing the aortic root in patients with bicuspid aortic valve disease. Curr Cardiol Rep 11:94-100

4. Balistreri CR, Pisano C, Candore G, Maresi E, Codispoti M, Ruvolo G (2013) Focus on the unique mechanisms involved in thoracic aortic aneurysm formation in bicuspid aortic valve versus tricuspid aortic valve patients: clinical implications of a pilot study. Eur J Cardiothorac Surg 43:e180-e186

5. Shiraya S, Miyake T, Aoki M, Yoshikazu F, Ohgi S, Nishimura M, Ogihara T, Morishita R (2009) Inhibition of development of experimental aortic abdominal aneurysm in rat model by atorvastatin through inhibition of macrophage migration. Atherosclerosis 202:34-40

6. Steinmetz EF, Buckley C, Shames ML, Ennis TL, VanvickleChavez SJ, Mao D, Goeddel LA, Hawkins CJ, Thompson RW (2005) Treatment with simvastatin suppresses the development of experimental abdominal aortic aneurysms in normal and hypercholesterolemic mice. Ann Surg 241:92-101

7. Schouten O, van Laanen JH, Boersma E, Vidakovic R, Feringa HH, Dunkelgrün M, Bax JJ, Koning J, van Urk H, Poldermans D (2006) Statins are associated with a reduced infrarenal abdominal aortic aneurysm growth. Eur J Vasc Endovasc Surg 32:21-26

8. Sukhija R, Aronow WS, Sandhu R, Kakar P, Babu S (2006) Mortality and size of abdominal aortic aneurysm at long-term follow-up of patients not treated surgically and treated with and without statins. Am J Cardiol 97:279-280

9. Jovin IS, Duggal M, Ebisu K, Paek H, Oprea AD, Tranquilli M, Rizzo J, Memet R, Feldman M, Dziura J, Brandt CA, Elefteriades JA (2012) Comparison of the effect on long-term outcomes in patients with thoracic aortic aneurysms of taking versus not taking a statin drug. Am J Cardiol 109:1050-1054

10. Stein LH, Berger J, Tranquilli M, Elefteraides JA (2013) Effect of statin drugs on thoracic aortic aneurysms. Am J Cardiol 112:1240-1245

11. Angeloni E, Vitaterna A, Pirelli M, Refice S (2015) Effects of statin therapy on ascending aorta aneurysms growth: a propensity-matched analysis. Int J Cardiol 191:52-55

12. Goel SS, Tuzcu EM, Agarwal S, Aksoy O, Krishnaswamy A, Griffin BP, Svensson LG, Kapadia SR (2011) Comparison of ascending aortic size in patients with severe bicuspid aortic valve stenosis treated with versus without a statin drug. Am J Cardiol 108:1458-1462
13. Lang RM, Badano LP, Mor-Avi V, Afilalo J, Armstrong A, Ernande L, Flachskampf FA, Foster E, Goldstein SA, Kuznetsova T, Lancellotti P, Muraru D, Picard MH, Rietzschel ER, Rudski L, Spencer KT, Tsang W, Voigt JU (2015) Recommendations for cardiac chamber quantification by echocardiography in adults: an update from the american society of echocardiography and the European association of cardiovascular imaging. J Am Soc Echocardiogr 28:1-39

14. Michelena HI, Desjardins VA, Avierinos JF, Russo A, Nkomo VT, Sundt TM, Pellikka PA, Tajik AJ, Enriquez-Sarano M (2008) Natural history of asymptomatic patients with normally functioning or minimally dysfunctional bicuspid aortic valve in the community. Circulation 117:2776-2784

15. Lancellotti P, Tribouilloy C, Hagendorff A, Moura L, Popescu BA, Agricola E, Monin JL, Pierard LA, Badano L, Zamorano JL, European Association of Echocardiography recommendations for the assessment of valvular regurgitation (2010) Part 1: aortic and pulmonary regurgitation (native valve disease). Eur $\mathrm{J}$ Echocardiogr 11:223-244

16. Baumgartner H, Hung J, Bermejo J, Chambers JB, Evangelista A, Griffin BP, Iung B, Otto CM, Pellikka PA, Quiñones M, American Society of Echocardiography, European Association of Echocardiography (2009) Echocardiographic assessment of valve stenosis: EAE/ASE recommendations for clinical practice. J Am Soc Echocardiogr 22:1-23

17. Goldstein SA, Evangelista A, Abbara S, Arai A, Asch FM, Badano LP, Bolen MA, Connolly HM, Cuéllar-Calàbria $\mathrm{H}$, Czerny M, Devereux RB, Erbel RA, Fattori R, Isselbacher EM, Lindsay JM, McCulloch M, Michelena HI, Nienaber CA, Oh JK, Pepi M, Taylor AJ, Weinsaft JW, Zamorano JL, Dietz H, Eagle K, Elefteriades J, Jondeau G, Rousseau H, Schepens M (2015) Multimodality imaging of diseases of the thoracic aorta in adults: from the American Society of Echocardiography and the European Association of Cardiovascular Imaging: endorsed by the Society of Cardiovascular Computed Tomography and Society for Cardiovascular Magnetic Resonance. J Am Soc Echocardiogr 28:119-182

18. Roman MJ, Devereux RB, Kramer-Fox R, O’Loughlin J (1989) Two-dimensional echocardiographic aortic root dimensions in normal children and adults. Am J Cardiol 64:507-512

19. Rizzo JA, Coady MA, Elefteriades JA (1998) Procedures for estimating growth rates in thoracic aortic aneurysms. J Clin Epidemiol 51:747-754

20. Roger VL, Go AS, Lloyd-Jones DM, Adams RJ, Berry JD, Brown TM, Carnethon MR, Dai S, de Simone G, Ford ES, Fox CS, Fullerton HJ, Gillespie C, Greenlund KJ, Hailpern SM, Heit JA, Ho PM, Howard VJ, Kissela BM, Kittner SJ, Lackland DT, Lichtman JH, Lisabeth LD, Makuc DM, Marcus GM, Marelli A, Matchar DB, McDermott MM, Meigs JB, Moy CS, Mozaffarian D, Mussolino ME, Nichol G, Paynter NP, Rosamond WD, Sorlie PD, Stafford RS, Turan TN, Turner MB, Wong ND, Wylie-Rosett J, American Heart Association Statistics Committee and Stroke Statistics Subcommittee (2011) Heart disease and stroke statistics-2011 update: a report from the American Heart Association. Circulation 123:e18-e209

21. Tadros TM, Klein MD, Shapira OM (2009) Ascending aortic dilatation associated with bicuspid aortic valve: pathophysiology, molecular biology, and clinical implications. Circulation 119: $880-890$

22. Barker AJ, Markl M, Bürk J, Lorenz R, Bock J, Bauer S, SchulzMenger J, von Knobelsdorff-Brenkenhoff F (2012) Bicuspid aortic valve is associated with altered wall shear stress in the ascending aorta. Circ Cardiovasc Imaging 5:457-466

23. Grewal N, Gittenberger-de Groot AC, Poelmann RE, Klautz RJ, Lindeman JH, Goumans MJ, Palmen M, Mohamed SA, Sievers HH, Bogers AJ, DeRuiter MC (2014) Ascending aorta dilation in 
association with bicuspid aortic valve: a maturation defect of the aortic wall. J Thorac Cardiovasc Surg 148:1583-1590

24. Detaint D, Michelena HI, Nkomo VT, Vahanian A, Jondeau G, Sarano ME (2014) Aortic dilatation patterns and rates in adults with bicuspid aortic valves: a comparative study with Marfan syndrome and degenerative aortopathy. Heart 100:126-134
25. Baumgartner I, Hirsch AT, Abola MT, Cacoub PP, Poldermans D, Steg PG, Creager MA, Bhatt DL, REACH Registry investigators (2008) Cardiovascular risk profile and outcome of patients with abdominal aortic aneurysm in out-patients with atherothrombosis: data from the Reduction of Atherothrombosis for Continued Health (REACH) Registry. J Vasc Surg 48:808-814 